British Journal of Nutrition (2022), 127, 1598

doi: $10.1017 / \mathrm{S} 0007114521004268$

(C) The Author(s), 2021. Published by Cambridge University Press on behalf of The Nutrition Society. This is an Open Access article, distributed under the terms of the Creative Commons Attribution licence (http://creativecommons.org/licenses/by/4.0/), which permits unrestricted re-use, distribution, and reproduction in any medium, provided the original work is properly cited.

\title{
Corrigendum
}

\section{Patient-Generated Subjective Global Assessment (PG-SGA) predicts length of hospital stay in lung adenocarcinoma patients - CORRIGENDUM}

Jilu Lang, Yanan Shao, Jiehao Liao, Jia Chen, Xuewen Zhou, Rong Deng, Wei-Jian Wang and Xian Sun

(First published online 10 September 2021)

DOI: https://doi.org/10.1017/S0007114521003500

The authors apologise for a misspelling of the seventh author's name: Wei-Jian Wang should instead read Wei-Jan Wang.

Also, the following financial support statement was erroneously omitted from the acknowledgements section:

This research was supported by China Medical University (CMU109-MF-55 to W.-J.W). 